\title{
Corrigendum
}

\section{Dietary addition of zinc-methionine influenced eggshell quality by affecting calcium deposition in eggshell formation of laying hens - CORRIGENDUM}

Lanlan Li, Liping Miao, Mingkun Zhu, Liansong Wang and Xiaoting Zou

(First published online 23 January 2020)

doi: https://doi.org/10.1017/S000711451900206X

The original text: first experimental group fed lowered level of organic $\mathrm{Zn}$ as $\mathrm{Zn}-\mathrm{Met}$ ( $40 \mathrm{mg} \mathrm{Zn}$ per kg of diet) (rate of chelation: 99.0\%, purity: $96.00 \%, 16.00 \%$ of zinc content, $80.00 \%$ of methionine, Novo International Trading Co., Ltd., Shanghai),

The amended text: first experimental group fed lowered level of organic $\mathrm{Zn}$ as $\mathrm{Zn}$-Met ( $40 \mathrm{mg} \mathrm{Zn}$ per kg of diet) (rate of chelation: 99.0\%, purity: $96.00 \%, 16.00 \%$ of zinc content, $80.00 \%$ of methionine, Novus International Trading Co., Ltd., Shanghai),

The reason: the company name was misspelled because of a typo. 